\title{
Aspect Based Sentimen Analysis Opini Publik Pada Instagram dengan Convolutional Neural Network
}

\author{
Muhammad Arief Rahman, Program Studi Teknologi Informasi, Herman Budianto, Teknologi Informasi Institut \\ Sains dan Teknologi Terpadu Surabaya, dan Esther Irawati Setiawan, Teknologi Informasi Institut Sains dan \\ Teknologi Terpadu Surabaya
}

\begin{abstract}
Abstrak - Internet sebagai sarana informasi dan komunikasi sudah sangat dikenal di kalangan masyarakat dalam menawarkan kemudahan dan fleksibilitas yang cukup memadai ketika menjadi media. Oleh karena itu opini publik terhadap Operator Telekomunikasi merupakan hal yang sangat penting untuk dijadikan patokan. Kadang-kadang ketika menganalisis ulasan online yang berkembang pesat ini, menjadi sulit untuk mengkategorikan apakah opini pelanggan puas atau tidak puas terhadap produk dan layanan. Selain itu, sebagai bagian dari peningkatan kualitas mereka, organisasi seperti jasa ini perlu mengklasifikasikan aspek produk dan layanan yang paling disukai pelanggan. Deep Learning adalah area baru dalam penelitian Machine Learning, yang telah diperkenalkan dengan tujuan menggerakkan. Convolutional Neural Network adalah salah satu contoh metode Deep Learning. Metode Convolutional Neural Network diharapkan dapat digunakan dalam pengimplementasian opini publik untuk keperluan data training yang dikumpulkan dari beragam data yang dianotasikan kelas sentimennya secara otomatis berdasarkan aspeknya masing-masing. Hasil dari penelitian menunjukkan dari 4 aspek dan 3 sentimen maka didapatkan nilai rata-rata precision, recall, dan f1score adalah precision - $\mathbf{9 5 . 8 0 \%}$, recall- $\mathbf{8 8 . 1 2 \%}$, f1_score-91.62\%. Bisa disimpulkan score representation ini dapat digunakan untuk klasifikasi sentimen.
\end{abstract}

Kata kunci : Convolutional Neural Network, Analisis Sentimen, Deep Learning, Social Network Analysis

\section{Pendahuluan}

$\mathrm{I}^{\mathrm{n}}$ nternet sebagai sarana informasi dan komunikasi sudah sangat dikenal di kalangan masyarakat dalam menawarkan kemudahan dan fleksibilitas yang cukup memadai ketika menjadi media. Salah satu contohnya adalah Instagram. Instagram adalah sebuah aplikasi berbagi foto dan video yang memungkinkan pengguna mengambil foto, mengambil video, menerapkan filter digital, dan membagikannya ke berbagai layanan jejaring sosial, termasuk milik Instagram sendiri. Toko online biasanya

Muhammad Arief Rahman, Departemen Teknologi Informasi, Institut Sains dan Teknologi Terpadu Surabaya, Surabaya, Jawa Timur, Indonesia (e-mail: rahman.malang@gmail.com)

Herman Budianto, Departemen Teknologi Informasi, Institut Sains dan Teknologi Terpadu Surabaya, Jawa Timur, Indonesia (e-mail: hb@stts.edu)

Esther Irawati Setiawan, Departemen Teknologi Informasi, Institut Sains dan Teknologi Terpadu Surabaya, Jawa Timur, Indonesia (email: esther@stts.edu) menyediakan fasilitas untuk memberikan ulasan yang dapat diakses oleh pengunjung. Ulasan berisi deskripsi singkat tentang kesaksian dari pengguna sebelumnya tentang layanan atau barang yang disediakan oleh penjual[1]. Social Network Services telah dikembangkan dalam berbagai bentuk[2][3]. Dengan pesatnya perkembangan teknologi ini, semakin banyak orang menuliskan opini mereka tentang produk atau jasa. Hal ini dimanfaatkan sebagai acuan para customer untuk mengetahui pendapat orang lain tentang produk atau jasa yang akan digunakan. Sebaliknya bagi produsen dapat digunakan sebagai media melacak kepuasan pelanggan. Instagram juga dapat digunakan sebagai alat untuk membangun reputasi digital secara global[4].

Operator telekomunikasi fixed-line dan operator multimedia di Indonesia yang memberikan layanan jaringan (network), layanan Internet, pusat data, serta layanan hosting dan cloud computing. Sebagai operator telekomunikasi, mengetahui kepuasan pelanggan merupakan hal yang sangat penting dikarenakan dapat menjadi patokan untuk perbaikan pada layanan yang diberikan oleh perusahaan. Dengan begitu kualitas layanan yang diberikan kepada masyarakat terutama kepada pelanggan Provider Internet sendiri dapat meningkat. Provider Internet telah memiliki cabang di 101 kota yang tersebar di Indonesia. Oleh karena itu opini publik terhadap Provider Internet merupakan hal yang sangat penting untuk dijadikan patokan.

Untuk menangkap sentimen kata yang digunakan penulis algoritma pembelajaran yang diawasi berdasarkan kesamaan antara kata-kata yang memperhitungkan peringkat ulasan sebelumnya untuk menangkap representasi kata vektor[5]. Analisis sentimen adalah pendekatan yang digunakan Natural Language Processing (NLP) untuk mengekstraksi, mengonversi, dan menafsirkan opini dari sebuah teks dan mengklasifikasikannya menjadi Sentimen positif, negatif atau netral[6]. Pebisnis selalu ingin tahu bagaimana opini public atau pelanggan mereka tentang produk dan layanan yang mereka berikan. Pelanggan berpotensi juga ingin mengetahui pendapat pengguna pelanggan sebelumnya sebelum mereka menggunakan layanan atau membeli produk[7]. Namun, untuk mengevaluasi umpan balik online itu, bukan masalah sederhana. Kadang-kadang ketika menganalisis ulasan online yang berkembang pesat ini, menjadi sulit untuk mengkategorikan apakah opini pelanggan puas atau tidak puas terhadap produk dan layanan. Selain itu, sebagai bagian dari peningkatan kualitas mereka, organisasi seperti jasa ini perlu mengklasifikasikan aspek produk dan layanan yang paling disukai pelanggan. Dan karena nilai informasi ini, terutama untuk menjaga kepercayaan dan retensi pelanggan, semuanya harus 
dilakukan tepat waktu. Masalahnya adalah sekitar $85 \%$ teks yang tersedia di internet memiliki format yang tidak terstruktur, sehingga perlu mengembangkan sistem yang secara otomatis dapat mengklasifikasikan aspek dan sentimen dari data teks online[8].

Deep Learning adalah area baru dalam penelitian Machine Learning, yang telah diperkenalkan dengan tujuan menggerakkan Machine Learning lebih dekat dengan salah satu tujuan aslinya yaitu Artificial Intelligence. Deep Learning adalah tentang belajar beberapa tingkat representasi dan abstraksi yang membantu untuk memahami data seperti gambar, suara, dan teks. Convolutional Neural Network adalah salah satu contoh metode Deep Learning. Berdasarkan penelitian dari Yoon Kim[9] bahwa klasifikasi kalimat menggunakan metode Convolutional Neural Network menghasilkan sesuatu yang baik sekali

Metode Convolutional Neural Network diharapkan dapat digunakan dalam pengimplementasian opini publik untuk keperluan data training yang dikumpulkan dari beragam data yang dianotasikan kelas sentimennya secara otomatis.

\section{TINJAUAN PUSTAKA}

\section{A. Penggunaan Word Embedding}

Pada paper [10] penulis melakukan klasifikasi teks dengan menggunakan word embedding lalu dikombinasikan dengan image embedding agar dapat melakukan tugas baru.. Ada beberapa definisi untuk apa Word Embeddings itu, tetapi dalam pengertian yang paling umum, Word Embeddings adalah representasi numerik dari kata-kata.

Model Word Embeddings dapat dibagi menjadi beberapa kategori utama :

- Metode berbasis hitungan

- Metode prediktif

Secara algoritmik, model-model ini serupa, kecuali bahwa CBOW memprediksi kata-kata target (misalnya 'mat') dari kata-kata konteks sumber ('kucing duduk di'), sedangkan skip-gram melakukan kebalikan dan memprediksi kata konteks-sumber dari target. kata-kata. Dalam model Skip-Gram, jaringan saraf dilatih melalui kumpulan besar di mana tujuan pelatihannya adalah untuk belajar perwakilan kata-kata yang baik dalam memprediksi kata-kata yang dekat. Sifat paling sederhana dari embeddings yang diperoleh dengan semua metode yang dijelaskan di atas adalah bahwa kata-kata yang mirip cenderung memiliki vektor yang sama.

\begin{tabular}{|c||c|c|c|}
\hline Relationship & Example 1 & Example 2 & Example 3 \\
\hline France - Paris & Italy: Rome & Japan: Tokyo & Florida: Tallahassee \\
big - bigger & small: larger & cold: colder & quick: quicker \\
Miami - Florida & Baltimore: Maryland & Dallas: Texas & Kona: Hawaii \\
Einstein - scientist & Messi: midfielder & Mozart: violinist & Picasso: painter \\
Sarkozy - France & Berlusconi: Italy & Merkel: Germany & Koizumi: Japan \\
copper - Cu & zinc: Zn & gold: Au & uranium: plutonium \\
Berlusconi - Silvio & Sarkozy: Nicolas & Putin: Medvedev & Obama: Barack \\
Microsoft - Windows & Google: Android & IBM: Linux & Apple: iPhone \\
Microsoft - Ballmer & Google: Yahoo & IBM: McNealy & Apple: Jobs \\
Japan - sushi & Germany: bratwurst & France: tapas & USA: pizza \\
\hline
\end{tabular}

Gambar 1 Hubungan berpasangan dalam embedding kata[11]

Penulis membahas masalah bahwa model berbasis vektor biasanya diarahkan untuk mewakili kata-kata dalam isolasi dan metode untuk membangun representasi untuk frasa atau kalimat telah menerima sedikit perhatian dalam literatur. Para penulis menyarankan penggunaan dua operasi komposisi, penggandaan dan penambahan (dan kombinasinya). Dengan cara ini penulis dapat menggabungkan embeddings kata ke frasa atau embeddings kalimat sambil mempertimbangkan properti penting seperti urutan kata dan hubungan semantik antara kata-kata (yaitu jenis komposisi semantik).

\section{B. Penggunaan CNN dengan memanfaatkan emoji}

Pada paper [12] penulis menggunakan emoji sebagai bahan acuan lain untuk mendeteksi sentiment tweet dengan metode Convolutional Neural Network. ketika menganalisis tweet dengan emoji yang seharusnya menyatakan senang atau marah, kami menemukan bahwa ada sekitar 20 hingga $40 \%$ tweets di mana sentimen teks dan emoji tidak konsisten. Mempertimbangkan hasil analisis ini, kami mengasumsikan bahwa sentimen tweet konsisten dengan emoji kecuali tweet dengan 9 , di mana sentimen emoji $40 \%$ tidak konsisten dengan teks. Pada bagian kedua dari

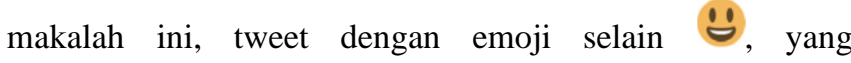
seharusnya konsisten dengan sentimen teks tweet dengan probabilitas lebih dari $60 \%$, serta tweet yang secara manual dinilai netral, digunakan sebagai pelatihan dan pengujian data model CNN. Pada bagian terakhir, tweet yang mengikuti distribusi sentimen dalam aliran tweet nyata digunakan sebagai data pengujian. Kami membandingkan beberapa variasi penyusunan tanggal pelatihan model CNN, dan mendiskusikan data pelatihan mana dan mana model modalnya yang optimal untuk mengidentifikasi sentimen tweets setelah distribusi sentimen dalam aliran tweets nyata.

Emoji seharusnya menjadi suplemen untuk mengekspresikan sentimen, tetapi survei awal penulis tentang emoji pada tweet Jepang mengungkapkan beberapa kasus yang menarik di mana emoji mengekspresikan sentimen yang tidak konsisten. Untuk menganalisis lebih lanjut hubungan emoji-sentimen, penulis mengumpulkan tweet Jepang dengan emoji oleh Twitter Streaming API1 dari 3 November 2016 hingga 23 Juni 2017. Lalu penulis mencicipi tweet dengan hanya satu emoji ( 0,0 , If atau (2)) dan menemukan tweet dengan $(\mathcal{C}$ lebih dari yang lain. Oleh karena itu untuk tweet dengan hanya satu emoji $(0)$, penulis menilai sentimen tweet secara manual hingga 100 tweet yang mana teks dan emoji mengekspresikan sentimen konsisten ditemukan. Untuk setiap emoji $\because$, ש atau penulis menilai sentimen secara manual untuk setiap kelas hingga 50 tweet yang mana teks dan emoji yang mengekspresikan sentimen konsisten ditemukan.

Seperti disebutkan pada tabel 1 , tweet dengan mengandung persentase tweet tertinggi dimana sentimen teks dan emoji tidak konsisten. Jadi, untuk mendapatkan hasil yang lebih baik, penulis memutuskan untuk tidak menggunakan bagian tweet ini. (Meskipun tweet dengan konten persentase tweet yang relatif tinggi di mana sentimen teks dan emoji tidak konsisten, karena ada jauh lebih sedikit tweet yang marah daripada bahagia tweet, penulis masih memutuskan untuk menggunakan bagian tweet ini). Secara khusus, 3.000 tweet dengan $\mathcal{O}, 3.000$ tweet dengan atau dipilih secara acak dari koleksi. Selain itu, penulis secara acak memilih 3.000 tweet netral dengan analisis 
manual. Berdasarkan hasil bahwa hanya sebagian kecil tweet yang mengekspresikan sentimen yang berlawanan dengan emoji, penulis menganggap bahwa sentimen tweet kira-kira konsisten dengan emoji. Setiap tweet diproses untuk menghilangkan URL, nama pengguna (mis. @Xxx) dan emoji. Selanjutnya, tweet ini diterapkan ke Mecab4 untuk dikonversi menjadi persamaan morfem. Kemudian penulis melakukan validasi silang 10 kali lipat pada kedua CNN dan SVM menggunakan 9.000 tweet yang telah diproses sebelumnya.

TABEL 1.

KLASIFIKASI SENTIMENT DARI TWEET DENGAN EMOJI[12].

\begin{tabular}{|c|c|c|c|c|c|}
\hline \multirow{2}{*}{\multicolumn{2}{|c|}{ Emoji }} & \multicolumn{2}{|c|}{$\begin{array}{c}\text { Number Of } \\
\text { Tweets }\end{array}$} & \multicolumn{2}{c|}{$\begin{array}{c}\text { Sentiments of emoji } \\
\text { and text }\end{array}$} \\
\cline { 3 - 6 } \multicolumn{2}{|c|}{} & $\begin{array}{c}\text { Collect } \\
\text { ed }\end{array}$ & $\begin{array}{c}\text { For } \\
\text { manual } \\
\text { Analysis }\end{array}$ & $\begin{array}{c}\text { Consist } \\
\text { ent }\end{array}$ & $\begin{array}{c}\text { Inconsiste } \\
\text { nt }\end{array}$ \\
\hline \multirow{2}{*}{$\begin{array}{c}\text { Happ } \\
\text { y }\end{array}$} & $\circlearrowright$ & 332573 & 120 & 100 & 20 \\
\hline \multirow{2}{*}{$\begin{array}{c}\text { Angr } \\
\text { y }\end{array}$} & Or & 37576 & 91 & 50 & 41 \\
\cline { 2 - 6 } & 13497 & 25161 & 70 & 50 & 35 \\
\hline
\end{tabular}

Untuk keperluan pengujian pada data yang mengikuti distribusi sentimen nyata, penulis secara acak memilih 1.000 Tweet dari 19 Januari 2017 hingga 22 Januari 2017 dan menilai sentimen secara manual. Akibatnya, tweet ini mencakup 180 tweet positif, 45 tweet negatif dan 775 tweet netral. Tweet netral memiliki jumlah yang luar biasa dan tweet negatif kurang dari lima persen.

\section{Klasifikasi Kalimat dengan CNN}

Pada paper [9] peneliti menggunakan metode Convolutional Neural Network untuk mengklasifikasi sebuah kalimat dan dibandingkan dengan 14 metode lain yaitu RAE : Recursive Autoencoders, MV-RNN: MatrixVector Recursive Neural Network, RNTN : Recursive Neural Tensor Network, DCNN : Dynamic Convolutional Neural Network, Paragraph-Vec, CCAE: Combinatorial Category Autoencoders, Sent-Parser: Sentiment analysisspecific parser, NBSVM, MNB: Naive Bayes SVM and Multinomial Naive Bayes, G-Dropout, F-Dropout: Gaussian Dropout and Fast Dropout, Tree-CRF: Dependency tree with Conditional Random Fields, CRF-PR : Conditional Random Fields with Posterior, SVMS : SVM with uni-bitrigrams.

Arsitektur model, yang ditunjukkan pada Gambar 1, adalah sedikit variasi dari Arsitektur NNCNCollobert et al. (2011). Misalkan xi $\in \mathrm{Rk}$ menjadi vektor kata kdimensional yang bersesuaian dengan kata ke-i dalam kalimat.

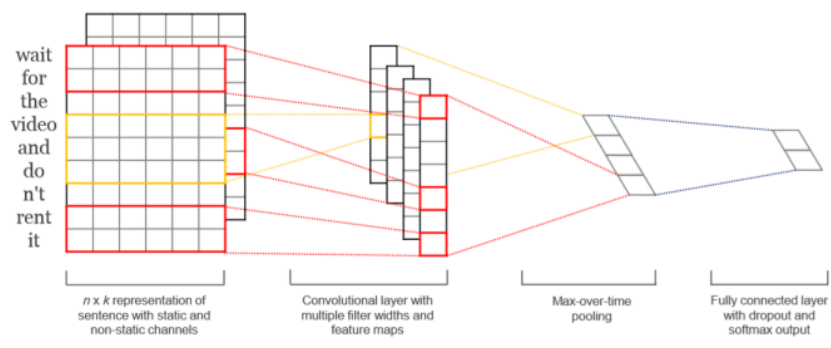

Gambar 2 Arsitektur model dengan dua saluran untuk contoh kalimat[9]

\section{Penggunaan Senticnet}

Pada paper [13] penulis menggunakan long shot term memory (LSTM) untuk menemukan kata kerja dan kata benda dalam sebuah kalimat menggunakan lexical subtitusi dan membuat 3 level konsep representasi pengetahuan untuk sentiment analisis, produk ini dinamakan dengan SenticNet 5. SenticNet 5 mengkode denotatif dan informasi konotatif yang umumnya dikaitkan dengan objek, tindakan, peristiwa, dan orang di dunia nyata. Ini akan keluar dari penggunaan kata kunci dan kata kunci yang terjadi secara kebetulan, dan bukannya bergantung pada makna tersirat yang terkait dengan konsep akal sehat. Lebih unggul daripada teknik sintaksis murni, SenticNet 5 dapat dengan mudah diekspresikan dengan menggunakan analisis analisis multikata yang tidak secara eksplisit menyampaikan emosi, tetapi lebih terkait dengan konsep yang melakukannya.

Sebuah kalimat $S$ dapat direpresentasikan sebagai urutan kata, yaitu, $S=[w 1, w 2, \ldots w n]$ di mana $n$ adalah jumlah kata dalam kalimat. Kalimat tersebut dapat dibagi menjadi beberapa bagian sehingga prefiks: $[\mathrm{w} 1, \ldots$ wi -1$]$ membentuk kalimat konteks kiri dengan 1 kata-kata dan sufiks: [wi $+1, \ldots$ wn] membentuk kalimat konteks yang tepat dengan kata-kata. Di sini, $\mathrm{c}=$ wi adalah kata target. Pada langkah pertama, penulis merepresentasikan kata-kata ini dalam representasi berdimensi rendah yang dikenal sebagai embeddings kata. Khususnya, kami menggunakan embedded word2vec 300 dimensi yang dilatih pada 3 miliar kata Google News corpus. Untuk mengekstrak fitur kontekstual dari subsensi ini, penulis menggunakan model biLSTM pada L dan C secara independent. Ketika biLSTM digunakan, operasi ini diterapkan di kedua arah urutan dan output untuk setiap catatan waktu digabung untuk membentuk representasi keseluruhan di luar kata kunci. Jadi, untuk setiap sensor mata, setelah menerapkan biLSTM, kita mendapatkan matriks fitur representasi berulang.

Model penulis hadir untuk sub-frasa yang penting dalam menyediakan konteks, penulis memasukkan modul perhatian di atas biLSTM untuk kalimat konteks. Modul perhatian terdiri dari jaringan saraf tambahan yang memiliki lapisan tersembunyi diikuti oleh output softmax (Gambar. 1). Ini menghasilkan vektor yang memberikan bobot yang sesuai dengan tingkat relevansi teks konteks di seluruh kalimat. Di bawah ini, kami menggambarkan rumusan perhatian yang diterapkan pada kalimat konteks.

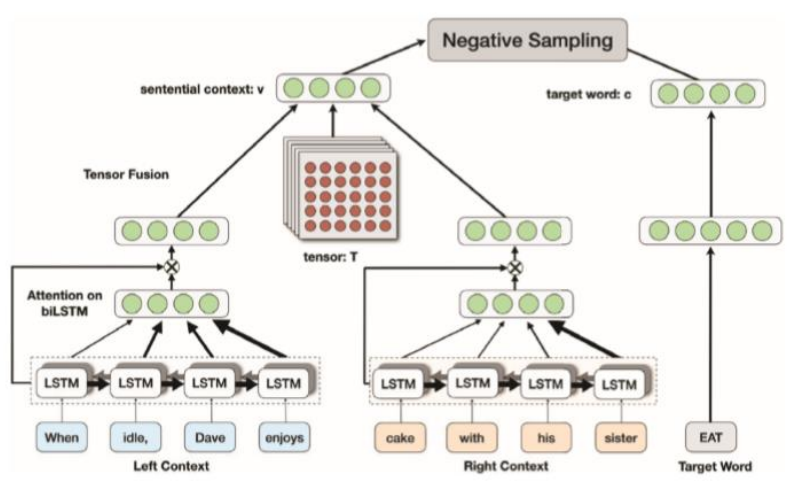

Gambar 3 Framework keseluruhan untuk context dan word embedding generation [13].

Penulis menguji SenticNet 5 (tersedia baik sebagai repositori2 mandiri XML dan sebagai API3) terhadap dua sumber daya sentimen terkenal: Blitzer Dataset (Blitzer, Dredze, dan Pereira 2007) yang kemudian dimodifikasi oleh (Poria et al. 2015) dan Movie Review Dataset dikembangkan (Pang dan Lee 2005). Blitzer Dataset terdiri dari ulasan produk di tujuh domain berbeda. Untuk setiap 
domain ada 1.000 ulasan positif dan 1.000 ulasan negatif. Kami memperoleh dataset ini, yang mengandung 3.800 kalimat positif dan 3.410 negatif, dari penulis (Poriaetal.2015). Sebaliknya, Movie Review Dataset telah direstrukturisasi dari dokumen ke level kalimat oleh Socheretal. (Socher et al. 2013c) dan berisi 4.800 kalimat positif dan 4.813 yang negative.

\section{E. Analisa Sentimen berbasis aspek untuk ulasan restoran.}

Pada paper [14] penulis melakukan analisis sentiment berdasarkan struktur yang terdiri dari aspek, kategori aspek, dan polaritas sentiment. Ada enam langkah dalam analisis sentimen berbasis aspek: ekstraksi entitas dan kategorisasi, ekstraksi aspek dan kategorisasi, klasifikasi polaritas sentimen, ekstraksi waktu, ekstraksi pemegang opini, dan pembentukan struktur opini.

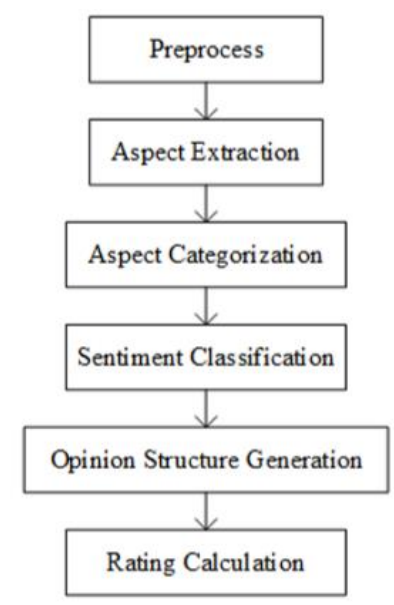

Gambar 4 Arsitektur Aplikasi[14]

Penulis menerapkan algoritma yang sama seperti dalam kategorisasi aspek untuk klasifikasi sentimen. penulis mendefinisikan dua label sentimen untuk setiap kategori dalam kalimat: positif dan negatif. Misalnya, sebuah kalimat memiliki kategori makanan dan tempat. Setiap kategori memiliki classifier sendiri untuk mengklasifikasikan sentimen kategori dalam kalimat. Untuk mengklasifikasikan polaritas sentimen, penulis menggunakan classifier untuk kategori makanan dan tempat. Untuk pembuatan struktur opini, penulis menggunakan model CBOW untuk menemukan kesamaan antara aspek yang diekstraksi dengan kata-kata awal untuk setiap kategori. Kategori yang memiliki skor kesamaan maksimum akan dipasangkan dengan aspek yang diekstraksi. Misalnya, sebuah kalimat memiliki kategori makanan dan tempat dan penulis ingin memasangkan "kue" dengan kategori dari kalimat tersebut. Pertama, penulis menemukan skor kesamaan untuk setiap kata benih untuk kategori makanan dan tempat. Skor kesamaan maksimum untuk kategori makanan dan tempat masing-masing adalah 0,2 dan 0,1. Setelah itu, kita bisa memasangkan "kue" dengan kategori makanan karena skor kesamaan untuk kategori makanan lebih tinggi dari kategori tempat.

\begin{tabular}{|l|r|}
\hline \multicolumn{1}{|c|}{ Label } & Total Sentence \\
\hline Food & 503 \\
\hline Service & 97 \\
\hline Price & 125 \\
\hline Place & 440 \\
\hline
\end{tabular}

Gambar 5 Label untuk kategori aspek dalam data training[14]

\begin{tabular}{|l|l|l|l|l|}
\hline \multicolumn{1}{|c|}{ Sentence } & Food & Service & Price & Place \\
\hline $\begin{array}{l}\text { Saya suka makanannya } \\
\text { (I like the food) }\end{array}$ & Yes & No & No & No \\
\hline $\begin{array}{l}\text { Tempat tetap nyaman, masakan tetap } \\
\text { lezat, dan pelayanan tetap ramah } \\
\text { (Place is still comfortable, cuisine is } \\
\text { still delicious, and service is still } \\
\text { friendly) }\end{array}$ & Yes & Yes & No & Yes \\
\hline
\end{tabular}

Gambar 6 Contoh training data untuk kategorisasi aspek[14]

Model ekstraksi aspek penulis dapat mengekstraksi beberapa aspek yang tidak muncul dalam data pelatihan, seperti "guramenya" (gurame) dan "jus strawberry" (jus strawberry). Karena model ini menggunakan fitur bag of $\mathrm{N}$ gram, klasifikasi token sangat tergantung dengan kemunculan kata, tag POS, dan cluster CBOW di jendela konteks. Salah satu contoh kesalahan klasifikasi terjadi dalam kalimat "baik rasa dan tempat yang nyaman untuk bersantai" (Baik dalam rasa dan tempat yang nyaman untuk bersantai). Aspek sebenarnya untuk kalimat adalah "rasa" (taste) dan "tempat" (place). Tetapi hasil ekstraksi adalah "tempat". Model gagal untuk mengekstrak "rasa" (rasa) sebagai aspek karena "rasa" (rasa) biasanya muncul bersamaan dengan kata-kata yang berkaitan dengan makanan, seperti "enak" (lezat) dan "makanan" (makanan) dalam data pelatihan. Tetapi kalimat itu tidak memiliki katakata yang berhubungan dengan makanan sehingga kesalahan klasifikasi terjadi. Kesalahan klasifikasi lain terjadi pada kalimat "paling enak nasi gorengnya, sate ayam, steak braga permai, dan chicken snitzel" (makanan yang paling enak adalah nasi goreng, sate ayam, steak braga permai, dan schnitzel ayam). Aspek yang diharapkan dari kalimat itu adalah "nasi gorengnya" (nasi goreng), "sate ayam", "steak braga permai" (steak braga permai), dan "snitzel ayam" (chicken schitzel). Tetapi hasil dari ekstraksi aspek adalah "nasi gorengnya". "Sate ayam" (sate ayam) dan "chicken snitzel" (chicken schnitzel) tidak diekstraksi sebagai aspek karena "sate" (sate) dan "snitzel" (schnitzel) tidak pernah muncul dalam data pelatihan. Meskipun "steak" dan "braga permai" muncul dalam data pelatihan, "steak" dan "braga permai" tidak pernah muncul secara bersamaan dalam data pelatihan dalam jendela konteks. Selain itu, "braga permai" muncul dalam data pelatihan sebagai nama restoran, bukan bagian dari nama makanan sehingga tidak pernah dilabeli sebagai aspek.

\begin{tabular}{|l|l|l|l|l|}
\hline \multicolumn{1}{|c|}{ Sentence } & Food & Service & Price & Place \\
\hline $\begin{array}{l}\text { Saya suka makanannya } \\
\text { (I like the food) }\end{array}$ & Positive & - & - & - \\
\hline $\begin{array}{l}\text { Tempat tetap nyaman, } \\
\text { masakan tetap lezat, dan } \\
\text { pelayanan tetap ramah } \\
\text { (Place is still comfortable, } \\
\text { cuisine is still delicious, and } \\
\text { service is still friendly) }\end{array}$ & Positive & Positive & - & Positive \\
\hline
\end{tabular}

Gambar 7 Contoh data training untuk klasifikasi sentiment[14]

\section{PERANCANGAN}

Pada pokok bahasan ini akan dibahas mengenai desain arsitektur dari system, alternative algoritma yang akan digunakan.

\section{a. Pre Processing}

Pada proses ini adalah proses yang di lakukan sebelum data siap di import pada sistem, proses ini dilakukan secara manual pada aplikasi pengolahan data office. 


\section{- Abbreviation Replacement}

Proses ini adalah perubahan singkatan yang dirubah menjadi sebuah teks, singkatan atau kata alay akan dirubah menjadi kata Bahasa Indonesia yang baik oleh tim social media analis.

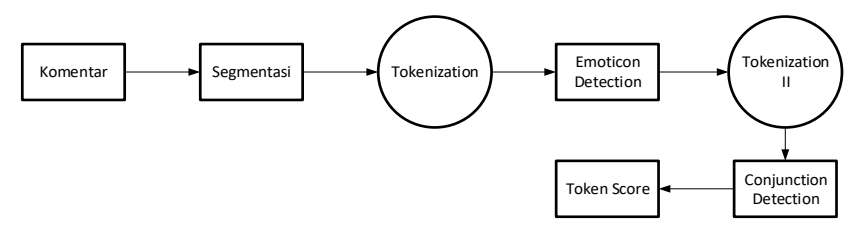

Gambar 8 Tahap pre-procesing.

- Segmentasi

Titik adalah satu-satunya tanda baca dianggap sebagai pemisah pada langkah ini, seperti koma atau titik koma dapat menjadi bagian dari emoticon.

\section{- Tokenization}

Pada langkah berikutnya, token yang diambil dari setiap kalimat. Pada kalimat ini hanya spasi putih dipertimbangkan untuk token terpisah, sejak pemisah lainnya, seperti tanda hubung, dapat menjadi bagian dari emoticon.

\section{- Deteksi emoticon}

Pencarian classifier dalam teks semua emoticon yang disimpan dalam dua file teks, yang berisi emoticon positif dan negatif.

\section{- Tokenization $I I$}

fase tokenization kedua ini, daftar kata hubung (dan, tapi, dll) dianggap sebagai pemisah terkemuka untuk mendapatkan set akhir token untuk setiap kalimat

- Deteksi Conjunction

Langkah selanjutnya terdiri dari mendeteksi dan label kata hubung dengan analisa struktur kalimat dengan daftar kata hubung (dan, tapi, dll). Dalam hal ini, dapat ditemukan komentar tersebut adalah kalimat majemuk atau tidak. Seperti "Biznet kecepatannya bagus sih, tapi dari 2 minggu complain belum ditanggapin"

- Token Skor

Tahap berikutnya terdiri dari menetapkan nilai untuk setiap token, 1 jika mengirimkan sentimen positif, 0 jika netral, dan -1 jika negatif.

\section{b. Arsitektur Sistem}

Proses training teks menggunakan metode convolutional neural network untuk ekstraksi fitur yang terdapat pada teks. Proses dilakukan dengan menggunakan dot product dari vector bobot atau kernel vector untuk setiap kata pada kalimat. Setiap kata tersebut direpresentasikan dengan word embedding, untuk dijadikan input pada convolutional neural network. Hasil dari convolutional neural network adalah 3 neuron yaitu positif, negative, dan netral.

Untuk proses pada teks menggunakan SenticNet 5, dilakukan ekstraksi konsep yang akan didapatkan nilai polarity berdasarkan konsep yang terdapat pada kalimat. Setiap konsep akan dilakukan pengecekan pada database SenticNet 5 dan menghasilkan nilai polarity yang digunakan untuk mendeteksi sentiment kalimat tersebut.

\section{c. Proses Word Embedding}

Proses ini merupakan teknik untuk merubah kalimat teks menjadi teks vector untuk mewakili makna dari kata tersebut. Ukuran vector bervariasi dari 50 - 300 dimensional vector. Nilai ini nantinya akan digunakan sebagai input pada proses training convolutional neural network. Setiap kalimat teks akan dihitung sesuai dengan kalimat terpanjang yang dimiliki oleh dataset. Kemudian apabila kalimat tersebut lebih pendek dari panjang kalimat terpanjang, maka sisa untuk melengkapi hingga akhir kalimat akan dinilai 0 atau diberi kata random yang tidak dapat dimengerti agar menjadi nilai 0. Atau yang dikenal dengan istilah padding, dengan menghitung setiap kalimat dengan panjang vector yang sama dengam menambahkan 0 di depan atau belakang kalimat. Untuk merubah kalimat menjadi vector, penulis menggunakan GloVe (Global Vector). Berikut adalah contoh dari word vector.

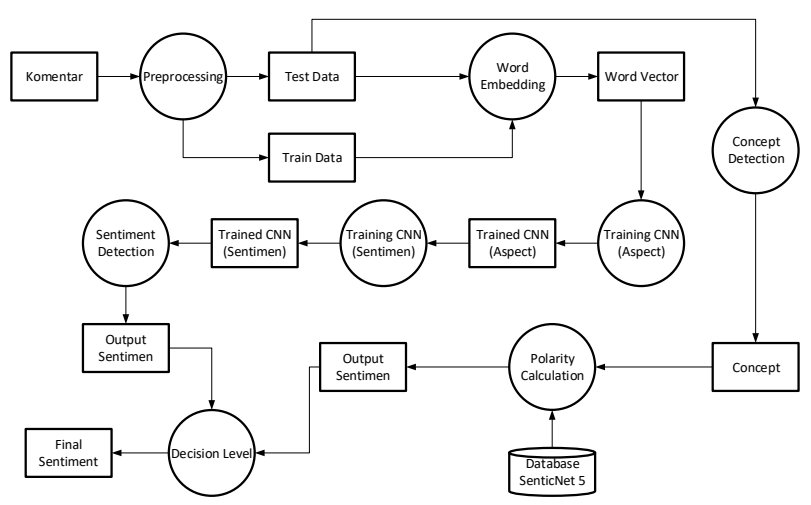

Gambar 9 Arsitektur Sistem.

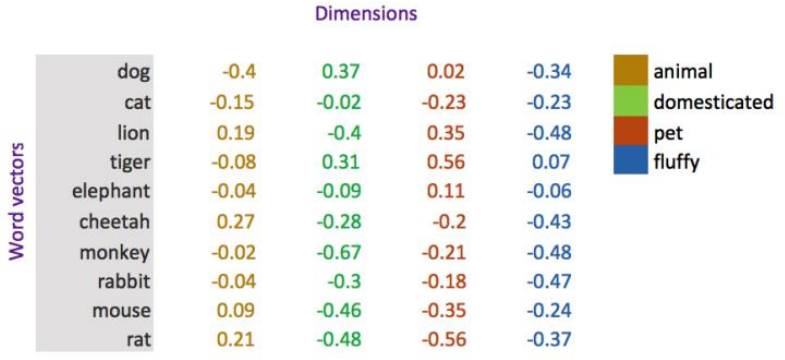

Gambar 10. Word Vector[15]

Setiap word vector memiliki nilai sebanyak dimensi yang telah ditentukan, nilai dari word vector suatu kata bias jadi memiliki kesamaan dengan kata yang sejenisnya. Contohnya adalah Lion dan Cheetah memiliki nilai yang tidak jauh pada dimensi animal.

d. Proses Training CNN

Pada proses ini metode Convolutional neural network akan digunakan untuk melakukan ekstraksi fitur yang terdapat pada teks. Proses yang terjadi pada convolutional layer adalah melakukan dot product dari vector dengan bobot atau kernel vector setiap kata pada kalimat untuk mendapatkan fitur yang lain. Seperti halnya tadi, setiap kata dalam kalimat direpresentasikan dengan word embedding, untuk dapat dijadikan input nilai pada convolutional neural network. Pada tahap awal, CNN akan training data untuk mendeteksi aspek dari kalimat. Sebagai bentuk sebuah analisa yang nantinya diharapkan mampu mempermudah pelanggan atau calon pelanggan untuk mendapatkan informasi ini. Seperti Layanan, Kecepatan, Coverage, dan Promosi Produk Biznet Home. Penelitian ini tahap klasifikasi awal adalah mengkelompokan data berdasarakan 
kelas-kelas yang disebutkan diatas. Termasuk pelabelan data training yang juga dikelompokan kedalam kelas tersebut. Pada tahap pertama klasifikasi yang harus dilakukan pada apliaksi adalah klasifikasi text terhadap aspek dimana data yang baru saja diperoleh di proses dengan data yang sudah disimpan sebagai data training. Kemudian akan dilakukan training CNN untuk mendeteksi sentiment dari tiap aspek dengan menghasilkan 3 class yaitu Positif, Netral, dan Negatif.

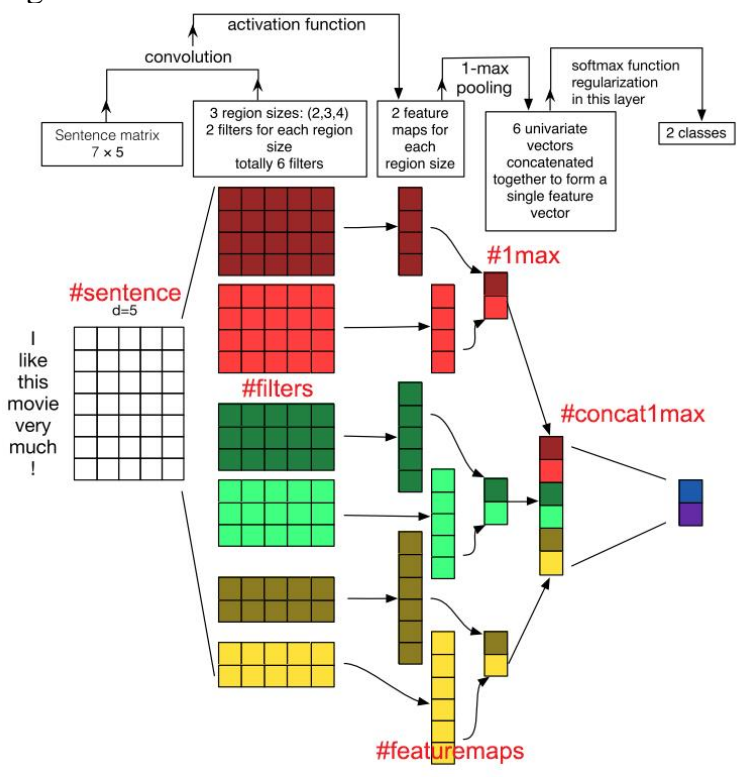

Gambar 11 Alur Kerja CNN[16]

Arsiteksur dari CNN yang akan digunakan yaitu dengan 1 convolutional layer dengan ukuran $2 \times 2$ dengan 100 kernel. Setiap convolutional layer diikuti dengan maxpool layer dengan ukuran 2 × 2, lalu terdapat fully connected layer dengan 500 neuron dan diakhiri dengan softmax layer dengan 4 neuron untuk mewakili class aspek (Layanan, Kecepatan, Coverage, dan Promosi) dan 3 neuron untuk mewakili class sentiment (Positif, Netral, dan Negatif).

\section{PENGUJIAN DAN ANALISIS}

\section{A. Dataset}

Dalam penelitian ini data diambil dari opini publik pada instagram pada akun @biznethome, menggunakan teknik crawling yang dilakukan oleh tim social media analis, jumlah data yang didapat sebanyak 1980, data yang dikumpulkan berupa text yang nantinya akan dilakukan pelabelan manual oleh tim social media analis. Data komentar yang dikumpulkan tidak berasal dari tulisan penulis. Setiap komentar akan diberikan label yang mewakili komentar tersebut. Label terdiri dari 3 jenis, yaitu positif, netral, dan negatif. Contoh data yang sudah terkumpul dapat dilihat pada Tabel 2.

TABEL 2

DISTRIBUSI KELAS PADA DATASET

\begin{tabular}{|l|l|l|l|l|}
\hline Aspect & Count & Pos & Netral & Neg \\
\hline Layanan & 692 & 29 & 575 & 88 \\
\hline Kecepatan & 122 & 4 & 45 & 73 \\
\hline Coveragae & 471 & 5 & 454 & 12 \\
\hline Promosi & 695 & 180 & 512 & 3 \\
\hline
\end{tabular}

Contoh 5 sample data yang diperoleh dapat dilihat pada Tabel 3.

Tabel 3

SAMPLE DATA YANG DIPEROLEH

\begin{tabular}{|l|l|l|}
\hline \multicolumn{1}{|c|}{ Komentar } & Aspek & \multicolumn{1}{|c|}{$\begin{array}{c}\text { Sentimen } \\
\text { Analisisi }\end{array}$} \\
\hline $\begin{array}{l}\text { Down lagi yaaaaa ??? Hmmm sudah } \\
\text { kuduga }\end{array}$ & Kecepatan & Negatif \\
\hline $\begin{array}{l}\text { BIZNET mau complaining internet } \\
\text { mati kemana? Saya posisi di ruko } \\
\text { harco mangga dua jalan mangga dua } \\
\text { raya Jakarta Pusat 10730 }\end{array}$ & Layanan & Netral \\
\hline $\begin{array}{l}\text { ID 20060219 tolong cek, dari tadi } \\
\text { lemot parah }\end{array}$ & Kecepatan & Netral \\
\hline $\begin{array}{l}\text { Untuk Kecamatan Lubuk Begalung } \\
\text { sudah ada coverannya ? }\end{array}$ & Coverage & Netral \\
\hline $\begin{array}{l}\text { kapan nih biznet bisa ada di lampung } \\
\text { nunggu banget nih }\end{array}$ & Coverage & Positif \\
\hline
\end{tabular}

\section{B. Pengujian}

Pengujian dilakukan pada Google Collaboratory.

\section{i. Preprocessing}

Pada tahapan ini dilakukan ekstraksi kata dari data raw yang diperoleh menggunakan librari rake_nltk sehingga didapat kata serapan dari setiap komentar, sehingga data siap untuk dilakukan ke pengujian tahap berikutnya. Hasil penggunaan librari tokenize ntlk dapat dilihat pada gambar 12 .

Fitted tokenizer on 3164 documents

40000 words in dictionary

Top 3 most common words are: [('kasih', 980), ('terima', 976), ('pakebiznet', 812)] Gambar 12. Hasil penggunaan tokenizer.

Setelah melakukan tokenizer pada kalimat, maka text tersebut dijadikan sequence untuk di proses pada tahapan selanjutnya. Berikut adalah hasil dari text sequence :

"Cimahi utara admin?" is converted into $[30,4,59,137,1230,333$, 126, 77, 10, 306, 173, 333, 126, $77,34,2,1,138]$

\section{ii. Pengujian Model}

- Aspect Model

Kami menggunakan pengaturan yang berbeda dari setiap model. Pada percobaan pertama, kami menggunakan Adagrad optimizer dengan perbandingan learning rate 0.1 . Pada percobaan kedua, kami menggunakan Adam optimizer dengan perbandingan learning rate 0.1. Pada percobaan ketiga, kami menggunakan rmsprop optimizer dengan perbandingan learning rate 0.1 .

Sebelum melakukan semua eksperimen, kami membandingkan 2 aspect model. Menggunakan Word Embedding (WE) dan model yang lain menggunakan kombinasi Word Embedding dan Convolutional Neural Network (WE+CNN). Hasil perbandingan pada model tersebut dapat dilihat pada table

TABEL 4 DISTRIBUSI KELAS PADA DATASET

\begin{tabular}{|l|l|l|l|}
\hline Model & Precision & Recall & F1-Score \\
\hline WE & 0.9536 & 0.6275 & 0.7568 \\
\hline WE+CNN & $\mathbf{0 . 9 5 8 5}$ & $\mathbf{0 . 8 0 6 9}$ & $\mathbf{0 . 8 7 5 9}$ \\
\hline
\end{tabular}




\section{- Sentiment Model}

Kami menggunakan pengaturan yang berbeda dari setiap model. Pada percobaan pertama, kami menggunakan Adam optimizer dengan perbandingan learning rate 0.1. Pada percobaan kedua, kami menggunakan rmsprop optimizer dengan perbandingan learning rate 0.1. Pada percobaan ketiga, kami menggunakan Adagrad optimizer dengan perbandingan learning rate 0.1 .

Sebelum melakukan semua eksperimen, kami membandingkan 2 aspect model. Menggunakan Word Embedding (WE) dan model yang lain menggunakan kombinasi Word Embedding dan Convolutional Neural Network (WE+CNN). Hasil perbandingan pada model tersebut dapat dilihat pada table

\section{TABEL 5}

DISTRIBUSI KELAS PADA DATASET

\begin{tabular}{|l|l|l|l|}
\hline Model & Precision & Recall & F1-Score \\
\hline WE & 0.9283 & 0.8613 & 0.8935 \\
\hline WE+CNN & $\mathbf{0 . 9 5 7 4}$ & $\mathbf{0 . 9 5 5 5}$ & $\mathbf{0 . 9 5 6 4}$ \\
\hline
\end{tabular}

Berikut adalah grafik untuk training dan validation loss. Dengan perbandingan $80 \%$ untuk data train dan $20 \%$ untuk data tes. Dengan 50 percobaan yang dilakukan. Data dari hasil train akan dicompile untuk digunakan untuk pengujian dengan data tes. Sehingga nanti akan didapat nilai dari precision, recall, dan f1-score dari penelitian ini. Sebelum memasuki training $\mathrm{CNN}$, teks memasuki proses Word Embedding. Untuk Word Embeding di penelitian ini penulis menggunakan metode Word Embeding GloVe (Global Vector). Berikut adalah hasil untuk Word Embeding menggunakan GloVe.

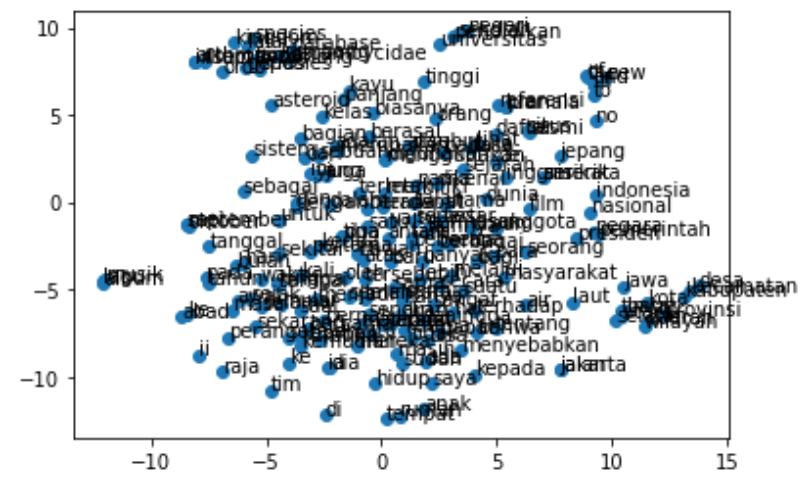

Gambar 13 Word Embedding GloVe

Data dari hasil Word Embeding akan dilakukan untuk train dengan CNN kemudian data akan divalidasi menggunakan precision, recall dan f1-score untuk dapat mengetahui hasil tingkat keakurasian dari data test dan data train. Berikut adalah tarining untuk mengetahui validation loss dari dataset.

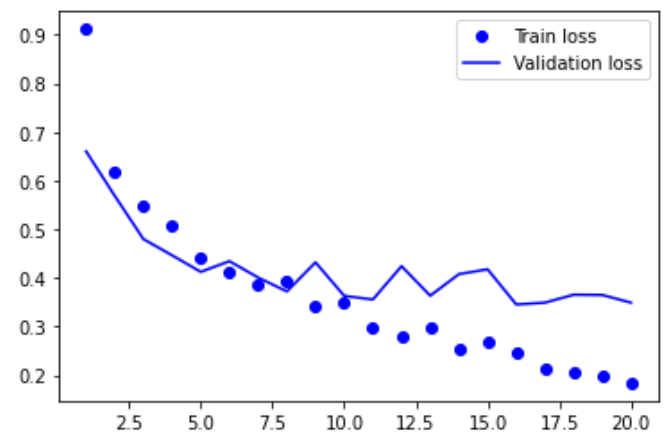

Gambar 14 Training dan validation loss
Kemudian untuk tingkat keakurasian dari Word Embeding GloVe dan Convolutional Neural Network dapat dilihat pada grafik berikut dengan percobaan yang sama.

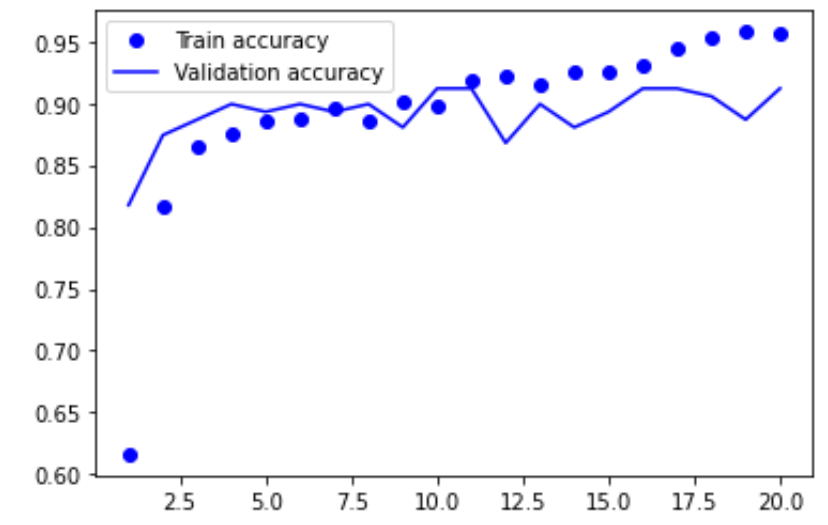

Gambar 15 Training dan validation accuracy

Kemudian untuk nilai f1-score dari setiap percoban dapat dilihat pada gambar 16.

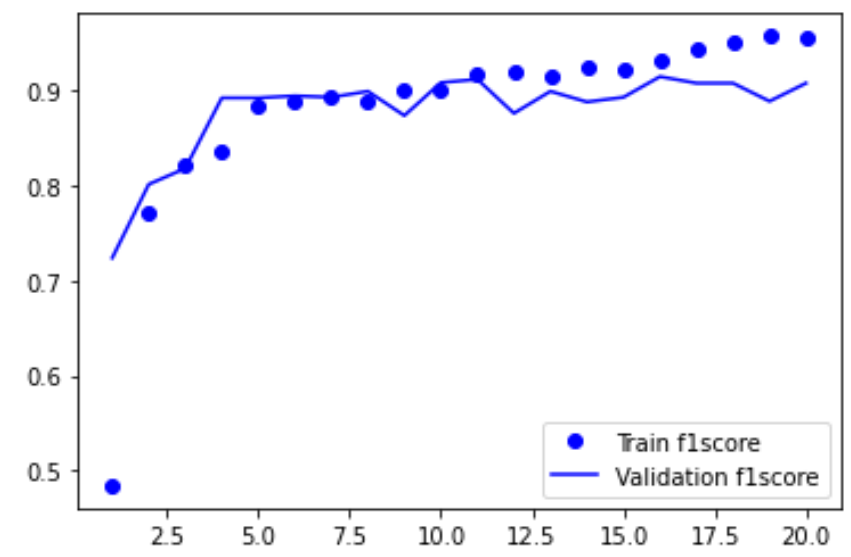

Gambar 16. Training F1 Score

\section{KESIMPULAN}

Berdasarkan hasil pengujian dari implementasi aspectbased sentimen analisis yang telah dilakukan, dapat disimpulkan bahwa dari dataset opini publik pada yang ada pada instagram tentang bagaimana respon pelanggan atau masyarakat umum terhadap perusahaan penyedia layanan internet dan komunikasi dapat dijadikan patokan untuk evaluasi terhadap layanan yang merekan berikan kepada pelanggan mereka.

Hasil evaluasi untuk data opini publik pada instagram mendapatkan hasil rata-rata precision $-95.80 \%$, recall$88.12 \%$, f1_score- 91.62\%. Sehingga dapat disimpulkan dengan melihat nilai fl-score pada penelitian ini tinggi, maka data yang disajikan dapat dijadikan sebagai patokan untuk perusahaan penyedia layanan internet agar dapat dijadikan evaluasi untuk kedepannya.

Sehingga peluang bisnis untuk memperbaiki market di zona tertentu dapat diimplementasikan.

\section{DAFTAR PUSTAKA}

[1] A. A. Lutfi, A. E. Permanasari, and S. Fauziati, "Corrigendum: Sentiment Analysis in the Sales Review of Indonesian Marketplace by Utilizing Support Vector Machine," J. Inf. Syst. Eng. Bus. 
Intell., vol. 4, no. 2, p. 169, 2018, doi: 10.20473/jisebi.4.2.169.

[2] S. Yu, "40 50대 사용자 유입을 위한

인스타그램 사용성 개선에 관한 연구 A Study on Usability Improvement of Instagram for Users in their 40s and 50s," vol. 9, no. 9, pp. 177-182, 2018.

[3] J. Mander, "GWI Social Summary," GWI white Pap., pp. 1-9, 2015, [Online]. Available: http://www.globalwebindex.net/hubfs/Reports/GWI _Social_Report_-

_Q3_2015_Summary.pdf?t=1453306719920\&utm_ campaign=Insight+Reports\&utm_source=hs_autom ation\&utm_medium $=$ email\&utm_content $=2207826$ 3\&_hsenc $=$ p2ANqtz-8p_-

_sZV7ZRvXkSeZW3f0npXAeby-

hKYHmWQbDg5Zs2IYNqh.

[4] E. Alshawaf and L. Wen, "Understanding digital reputation on Instagram: A case study of social media mavens," Proc. 2nd Eur. Conf. Soc. Media ECSM 2015, no. July, pp. 19-27, 2015, [Online].

Available:

https://www.researchgate.net/publication/28059914 0_Understanding_Digital_Reputation_on_Instagram _A_Case_Study_of_Social_Media_Mavens?enrichI d=rgreq-22fe062f9b4f4f2eefe67fe263c89dbb-

XXX\&enrichSource $=$ Y292ZXJQYWdlOzI4MDU5 OTE0MDtBUzoyNjM4Nzg3ODUzNjgwNjRAMT QzO.

[5] J. Jong, "Predicting Rating with Sentiment Analysis," pp. 1-5, 2011.

[6] B. Agarwal, N. Mittal, P. Bansal, and S. Garg, "Sentiment analysis using common-sense and context information," Comput. Intell. Neurosci., vol. 2015, 2015, doi: 10.1155/2015/715730.

[7] U. T. Gürsoy, "Social Media Mining and Sentiment Analysis for Brand Management," pp. 497-511, 2017.

[8] C. Fiarni, H. Maharani, and R. Pratama, "Sentiment analysis system for Indonesia online retail shop review using hierarchy Naive Bayes technique," 2016 4th Int. Conf. Inf. Commun. Technol. ICoICT 2016, vol. 4, no. c, 2016, doi:

10.1109/ICoICT.2016.7571912.

[9] Y. Kim, "Convolutional Neural Networks for Sentence Classification,” 2014, doi: 10.3115/v1/D14-1181.

[10] A. Mandelbaum and A. Shalev, "Word Embeddings and Their Use In Sentence Classification Tasks," 2016, [Online]. Available: http://arxiv.org/abs/1610.08229.

[11] T. Mikolov, K. Chen, G. Corrado, and J. Dean, "Efficient Estimation of Word Representations in Vector Space," pp. 1-12, 2013, doi: $10.1162 / 153244303322533223$.

[12] H. Cui, Y. Lin, and T. Utsuro, "Sentiment Analysis of Tweets by CNN utilizing Tweets with Emoji as Training Data," 2018, [Online]. Available: http://www.cl.ecei.tohoku.ac.jp/ msuzuki/jawiki_vector/.

[13] E. Cambria, S. Poria, D. Hazarika, and K. Kwok, "SenticNet 5: Discovering Conceptual Primitives for Sentiment Analysis by Means of Context
Embeddings," in Association for the Advancement of Artificial Intelligence, 2018, doi: http://dx.doi.org/10.1016/j.ijporl.2014.01.009.

[14] D. Ekawati and M. L. Khodra, "Aspect-based sentiment analysis for Indonesian restaurant reviews," Proc. - 2017 Int. Conf. Adv. Informatics Concepts, Theory Appl. ICAICTA 2017, 2017, doi: 10.1109/ICAICTA.2017.8090963.

[15] Jayesh Bapu Ahire, "Introduction to Word Vectors." https://medium.com/@jayeshbahire/introduction-toword-vectors-ea1d4e4b84bf (accessed Jan. 09, 2019).

[16] L. Li, L. Xiao, N. Wang, G. Yang, and J. Zhang, "Text classification method based on convolution neural network," 2017 3rd IEEE Int. Conf. Comput. Commun. ICCC 2017, vol. 2018-Janua, pp. 19851989, 2018, doi:

10.1109/CompComm.2017.8322884. 